\title{
Acquisition Method for Micro-gap Oil Film Morphology of Hydrostatic Workbench Having Double Rectangular Cavities under Working Conditions of High-Speed and Heavy-Load
}

\author{
X. D. Yu ${ }^{1 \dagger}$, S. B. Wang ${ }^{1}$, B. Y. Tang ${ }^{1}$, D. F. Zhou ${ }^{1}$, S. H. Li ${ }^{1}, Z^{2} \operatorname{Han}^{1}$, M. M. Chen ${ }^{1}$, R. M. \\ Zhang ${ }^{1}$, J. H. Jiao ${ }^{2}$ and J. F. Wang ${ }^{2}$
}

${ }^{1}$ Harbin University of Science and Technology, Key Laboratory of Advanced Manufacturing and Intelligent Technology, Ministry of Education, Harbin, Heilongjiang, 150000, China

${ }^{2}$ Qiqihar Heavy CNC Equipment Corp, Qiqihar, Heilongjiang, 161000, China

†Corresponding Author Email: yuxiaodong@hrbust.edu.cn

(Received May 24, 2021; accepted October 20, 2021)

\begin{abstract}
When the hydrostatic workbench is running under high-speed overload conditions, the friction by-product is partially placed, causing the micro-gap oil film to be smaller, and the tribology is exposed. The oil film morphology of hydrostatic workbench directly affects its lubrication performance, and the oil film morphology is determined by deformation of bearing friction pairs and the oil film morphology is extremely difficult to obtain. This study will provide an acquisition method for the oil film morphology through the deformation of the bearing friction pair, and the deformation prediction of hydrostatic workbench having double rectangular cavities in heavy type vertical lathe has studied based on ANSYS WORKBENCH, and these are helpful to further investigate oil film shape under the working conditions of high-speed and heavyload. The oil film clearance test rig was established, and the simulation results were verified, which verified the effectiveness of the proposed numerical simulation method. It can be concluded that the rotational speed has a greater impact on the oil film thickness than that of load, and the oil film thickness of downstream side is smaller than that of upstream side, and oil film thickness changes more quickly inside of oil sealing edge than that of outside, and the friction behavior and failure mechanism of this kind of bearing are proved.
\end{abstract}

Keywords: Hydrostatic workbench; Micro-gap oil film morphology; Friction pairs deformation; Heat fluid structure interaction method; High-speed and heavy-load working conditions

\section{NOMENCLATURE}

$\begin{array}{ll}b_{2}(i) & \text { volume components } \\ c_{k l} & \text { thermal expansion coefficient respectively } \\ D_{i j k l} & \text { structure flexibility matrix } \\ f & \text { unit forces } \\ p & \text { pressure } \\ S_{T} & \text { heat source } \\ T & \text { oil film temperature } \\ t & \text { time } \\ u & \text { components of speed vector in x directions } \\ u_{2}(i) & \text { displacement }\end{array}$

\section{INTRODUCTION}

The hydrostatic workbench is one of the key components in heavy type $\mathrm{CNC}$ machining equipments, and its performance directly affects the safe and stable operation of CNC machining

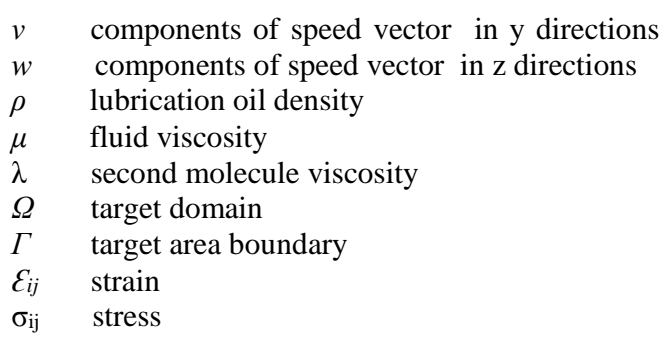

equipments, hydrostatic workbench is usually used in high-speed, overload or extreme working conditions. With the increase in the size and complex structure of the rotational workbench and base, the working conditions of hydrostatic thrust bearings have further deteriorated. These occasions 
require higher and higher bearing lubrication performance, which makes researchers pay more attention to the lubrication performance of hydrostatic bearings.

Huang et al. (2018) solved the thermal characteristics and deformation of hydrostatic bearing in vertical machine tool, discussed and studied the cooling structure of the hydrostatic bearing, and provided a theoretical basis for further solving the problem of deformation caused by the temperature, and the cooling structure has been optimized. Zhang et al. (2019a,b, 2021) studied the sudden rise of oil film temperature in the operation of hydrostatic thrust bearing. Based on the lubrication mechanism of bearing friction pair, the hot oil carrying phenomenon of oil film of inclined plane type double rectangular oil pad hydrostatic bearing was expounded, and the temperature distribution of oil film and the occurrence law of hot oil carrying were studied. Zhang (2016) found that oil film temperature, oil film pressure and deformation would affect its radius clearance, and controlling these parameters was of vital importance to improving the machining accuracy of ultra-precision machine tools. Wang (2016) studied the bearing characteristics and fluid-solid-heat coupling laws of large-scale heavy-duty hydrostatic turntables to solve the problems of poor hydrostatic rail running stability, low machining accuracy and scratching accidents. Ding et al. (2019) analyzed the influence of lubricating oil viscosity on the temperature change of the oil film in the clearance. Guo and Cui (2016) studied the hydrodynamic bearing and used the thermal-fluid-structure coupled finite element method to explore the influence of temperature field distribution, pressure field distribution and deformation field of the oil film between the bearing and the worktable on the machining accuracy, which provided a theoretical basis for the prediction of the oil film. Yu et al. $(2018,2020,2021)$ studied the oil film stiffness and thickness of hydrostatic thrust bearing, and concluded that with the increase of rotating table speed, the lubricating oil viscosity decreased, the clearance oil film became thinner and the oil film stiffness became larger. Xu et al. (2019) investigated influence of dimple shape on tribofilm formation and tribological properties of textured surfaces under full and starved lubrication, and concluded lubrication conditions have significant influences on the formation of tribofilms and then affect tribological behavior. $\mathrm{Xu}$ et al. (2019) presented synergistic effects of electroless piston ring coatings and nano-additives in oil on the friction and wear of a piston ring/cylinder liner pair to enhance the tribological of piston ring-cylinder liner pair in engines. Luo et al. (2021) studied Surface characterization of steel/steel contact lubricated by PAO6 with novel black phosphorus nanocomposites and the results showed that the rubbed surfaces became smooth and little wear with the addition of the nanocomposites. Wang et al. (2014) investigated the influence of guide rail deformation on stiffness, flow characteristics, pressure ratio and film thickness, and found that the guide rail deformation reduces the rigidity of the hydrostatic guide rail and increases the flow rate. Chai et al. (2018) studied the local deformation of aerostatic bearings under considering the influence of temperature through numerical analysis methods. Tang et al. (2017) explored the influence of spindle revolution and oil supply pressure on the temperature field of oil film in the clearance of hydrostatic and hydrodynamic hybrid bearing, and established a thermal-fluidic-structure coupling model to analyze its thermal deformation. Mustapha et al. (2012) theoretically studied the influence of pad deformation on the stability and dynamic characteristics of journal bearings under slight harmonic vibration working conditions. Stefan I et al. (2013) studied the flow performance and the oil cavity pressure of a hydrostatic journal bearing by using numerical method and experimental results. Saurabh et al. (2013) studied three-dimensional parametric and numerical experimental flow visualization of a six-pocket hydrostatic journal bearing. Mojtaba et al. (2014) investigated THD characteristics of Rayleigh step bearings under incompressible, laminar, and steady working conditions. Novikov et al. (2004) introduced the method of optimizing the oil film temperature rise and deformation of circular cavity hydrostatic thrust bearing, and greatly improved the production efficiency and operation accuracy.

With the requirements for bigger carrying capacity and higher speed of hydrostatic workbench, the deformation of friction pairs will cause the bearing clearance to decrease under working conditions of high-speed and heavy-load, which limits the high precision and stable operation of the hydrostatic workbench. The purpose of this paper is to obtain the gap oil film shape by studying the deformation of the friction pairs and to explore the failure mechanism of the hydrostatic workbench.

\section{HydROSTATIC WORKBENCH}

\subsection{Working Principle}

The working principle of hydrostatic workbench having double rectangular cavities is shown in Fig. 1. Externally pressurized lubrication oil is supplied into oil cavity through a pump, and forms a lubrication oil layer, then it lifts the rotational workbench and external load.

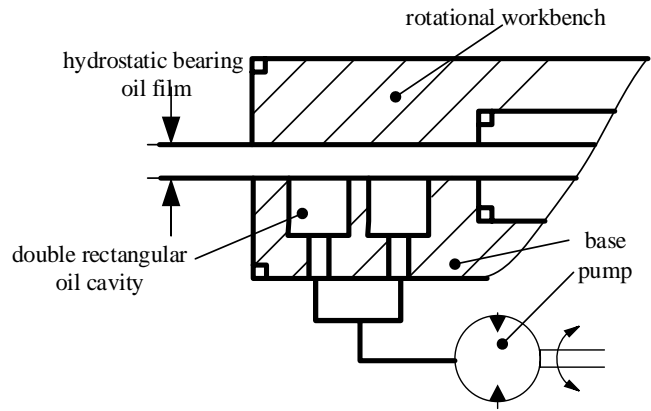

Fig.1. Working principle of hydrostatic workbench. 


\subsection{Structure and Hydraulic Principle}

The oil cavity structure of hydrostatic workbench having double rectangular cavities is shown as Fig. 2 , and the hydrostatic bearing lubrication principles is shown in Fig. 3. The hydraulic working principle of hydrostatic workbench is shown in Fig. 4.

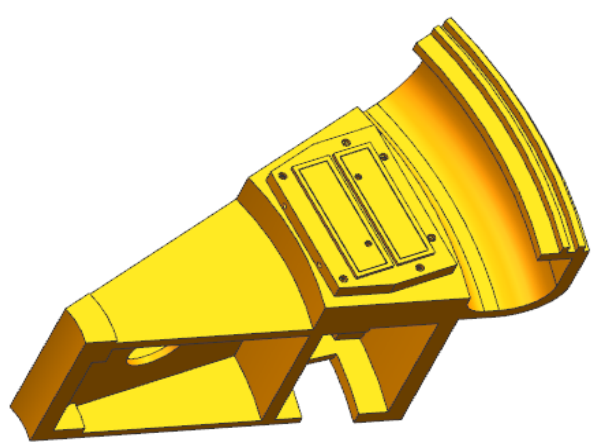

Fig. 2. Oil recess of hydrostatic bearing workbench.

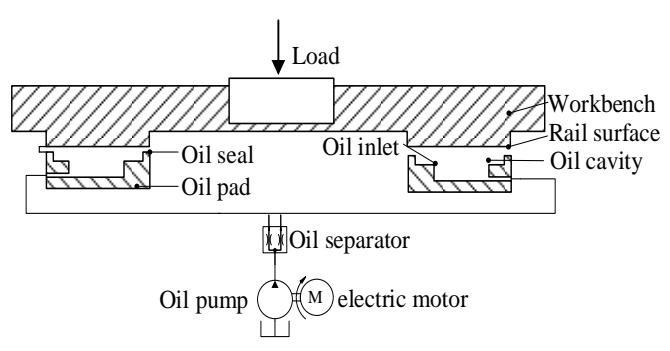

Fig. 3. Hydrostatic bearing lubrication principles.

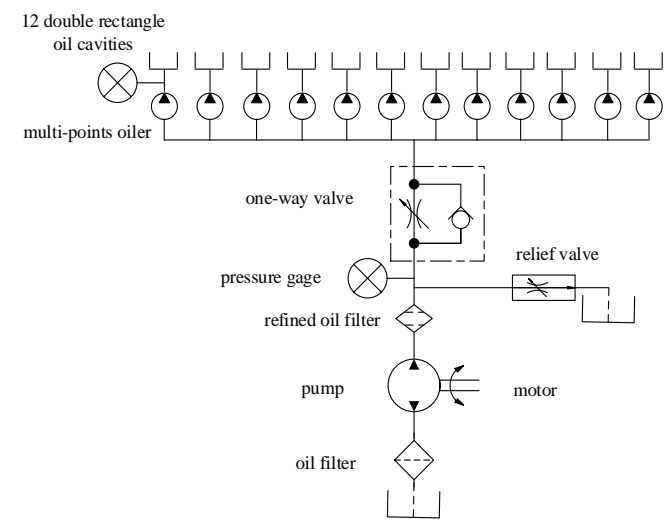

Fig. 4. Hydraulic working principle of hydrostatic workbench.

\section{Field and Oil Cavity Pressure Field Solushin of The Problem}

In order to calculate the deformation of the friction pair, the temperature field and pressure field of the gap oil film must be obtained first, and the temperature field and pressure field are taken as the body load and applied to the corresponding friction pair to obtain the deformation. Solution of temperature field and pressure field of gap oil film is as follows.

(1) Gap oil film model of hydrostatic workbench is built through UG software.

(2) Gap oil film model is imported to ANSYS ICEM CFD, and then mesh the oil film model.

(3) The boundary conditions and material properties are defined by ANSYS CFX.

(4)The governing equations are solved based on the finite volume method (FVM), and the highresolution method is adopted for the format convection discrete terms. The boundary conditions used for the solution of temperature field and pressure field of micro-gap oil film performance are as follows. The external pressure of oil recess is $0.1 \mathrm{MPa}$. The external temperature of lubrication oil is the temperature of surrounding atmosphere. The temperature of input lubricant oil is the temperature of the oil tank. The convergence criterion of RMS is $10^{-4}$, and results of the convergence are good, and meet the accuracy requirements. Mesh model and grid quality of oil film are shown as Fig. 5 and Fig. 6. Boundary conditions are shown as Fig. 7. Convergent iterative curve is shown as Fig. 8.

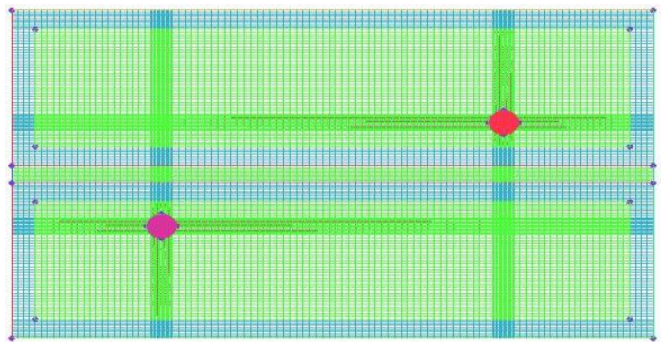

Fig. 5. Mesh model of oil film.

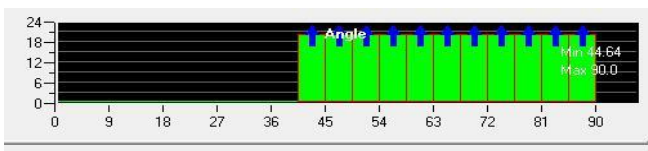

Fig. 6. Grid quality of oil film.

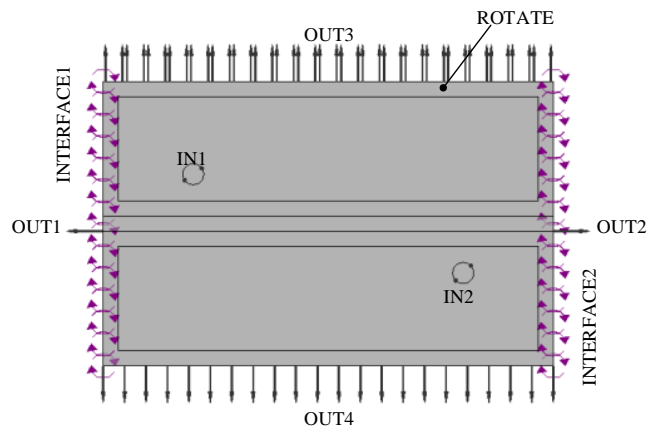

Fig. 7. Boundary conditions

The gap oil film temperature field and oil cavity pressure fields was simulated, as shown in Fig. 9 and Fig. 10. 


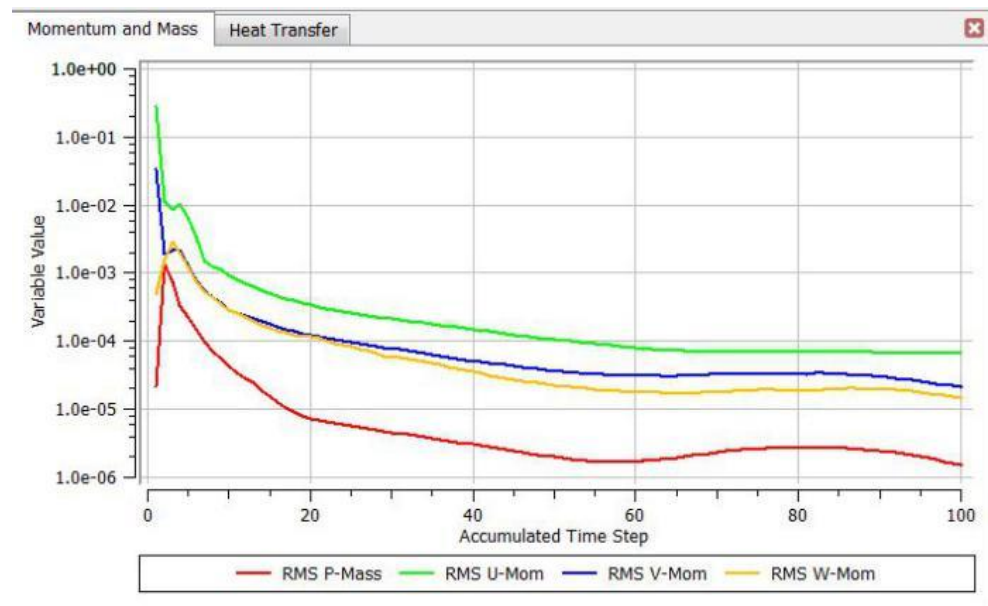

Fig. 8. Convergent iterative curve.

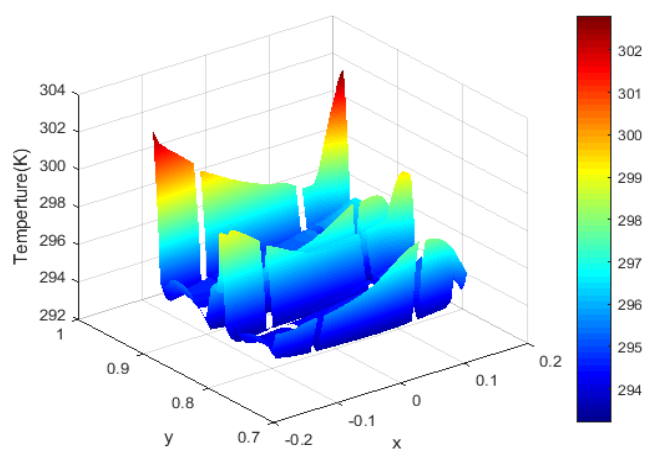

Fig. 9. Oil film temperature field at 30t-50r/min.

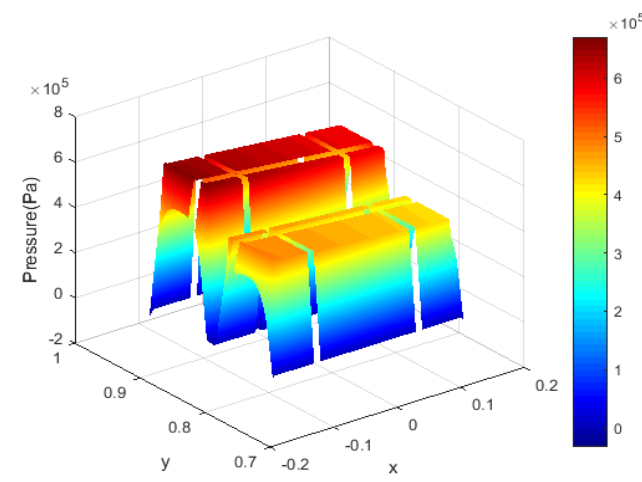

Fig.10 Oil recess pressure field at 30t-50r/min

\section{FRICTION PAIRS DEFORMATION}

The oil film shape is determined by deformation of bearing friction pairs of hydrostatic workbench, and the deformation of bearing friction pairs must meet fluid heat interaction equation and heat structure interaction equation.

\subsection{Fluid Heat Interaction Equation}

The flow of lubrication oil in the micro-clearance for the hydrostatic bearing workbench must meet the continuity equation, momentum equation and energy equation.

$\frac{\partial \rho}{\partial t}+\frac{\partial(\rho u)}{\partial x}+\frac{\partial(\rho v)}{\partial y}+\frac{\partial(\rho w)}{\partial z}=0$

where $\mathrm{t}$ is time (s); $u, v$ and $w$ are components of speed vector $\vec{u}$ in $\mathrm{x}, \mathrm{y}$ and $\mathrm{z}$ directions; $\rho$ is lubrication oil density $\left(\mathrm{kg} / \mathrm{m}^{3}\right)$.

The oil film in this study is $0.8 \mathrm{MPa}$, the lubrication oil is considered incompressible, then Eq. (1) can be rewritten as follows.

$\frac{\partial u}{\partial x}+\frac{\partial v}{\partial y}+\frac{\partial w}{\partial z}=0$

The density of lubrication oil is constant under conditions of low temperature and low pressure, Eq. (2) is expressed as follows.

$$
\begin{aligned}
& \frac{\partial(\rho u)}{\partial t}+\frac{\partial(\rho u u)}{\partial x}+\frac{\partial(\rho v u)}{\partial y}+\frac{\partial(\rho w u)}{\partial z}= \\
& \rho f_{x}-\frac{\partial \rho}{\partial x}+\frac{\partial}{\partial x}\left[2 \mu \frac{\partial u}{\partial x}+\lambda\left(\frac{\partial u}{\partial x}+\frac{\partial v}{\partial y}+\frac{\partial w}{\partial z}\right)\right] \\
& +\frac{\partial}{\partial y}\left[\mu\left(\frac{\partial u}{\partial y}+\frac{\partial v}{\partial x}\right)\right]+\frac{\partial}{\partial z}\left[\mu\left(\frac{\partial w}{\partial x}+\frac{\partial u}{\partial z}\right)\right] \\
& \frac{\partial(\rho v)}{\partial t}+\frac{\partial(\rho u v)}{\partial x}+\frac{\partial(\rho v v)}{\partial y}+\frac{\partial(\rho w v)}{\partial z}= \\
& \rho f_{y}-\frac{\partial \rho}{\partial y}+\frac{\partial}{\partial y}\left[2 \mu \frac{\partial v}{\partial y}+\lambda\left(\frac{\partial u}{\partial x}+\frac{\partial v}{\partial y}+\frac{\partial w}{\partial z}\right)\right] \\
& +\frac{\partial}{\partial z}\left[\mu\left(\frac{\partial v}{\partial z}+\frac{\partial w}{\partial y}\right)\right]+\frac{\partial}{\partial x}\left[\mu\left(\frac{\partial u}{\partial y}+\frac{\partial v}{\partial x}\right)\right] \\
& \frac{\partial(\rho w)}{\partial t}+\frac{\partial(\rho u w)}{\partial x}+\frac{\partial(\rho v w)}{\partial y}+\frac{\partial(\rho w w)}{\partial z}= \\
& \rho f_{z}-\frac{\partial \rho}{\partial z}+\frac{\partial}{\partial z}\left[2 \mu \frac{\partial w}{\partial z}+\lambda\left(\frac{\partial u}{\partial x}+\frac{\partial v}{\partial y}+\frac{\partial w}{\partial z}\right)\right] \\
& +\frac{\partial}{\partial x}\left[\mu\left(\frac{\partial w}{\partial x}+\frac{\partial u}{\partial z}\right)\right]+\frac{\partial}{\partial y}\left[\mu\left(\frac{\partial v}{\partial z}+\frac{\partial w}{\partial y}\right)\right]
\end{aligned}
$$

where $f_{x}, f_{y}, f_{z}$ are unit forces $(\mathrm{N}), p$ is pressure (Pa), $\mu$ is the fluid viscosity, $\lambda$ is the second molecule viscosity. 


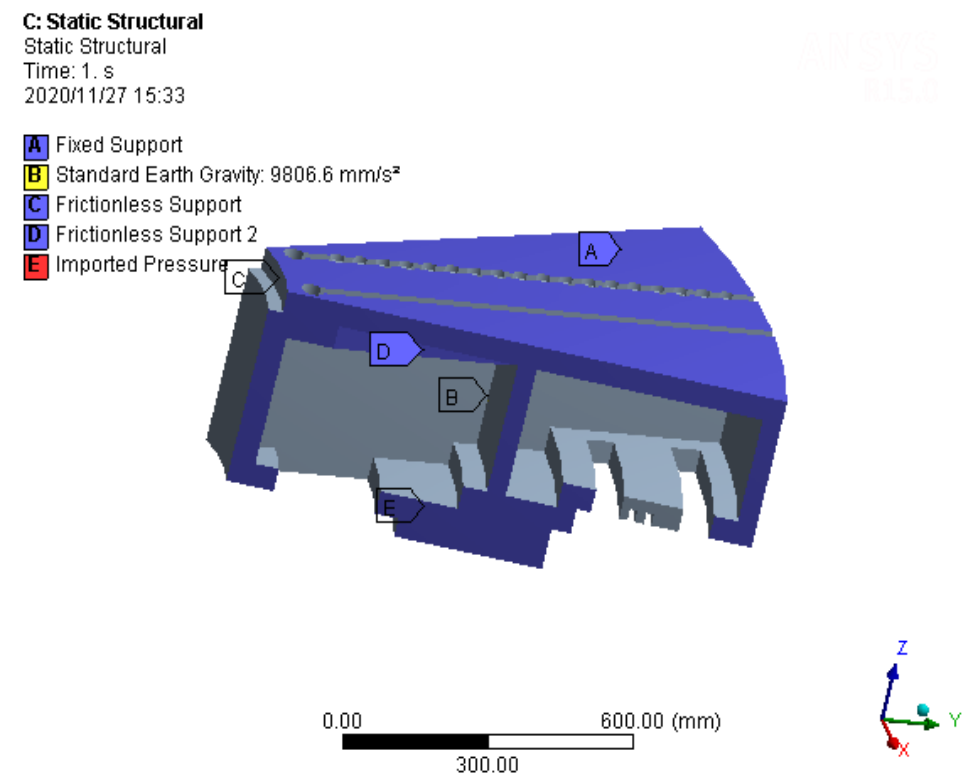

Fig. 11. Boundary conditions of rotational worktable.

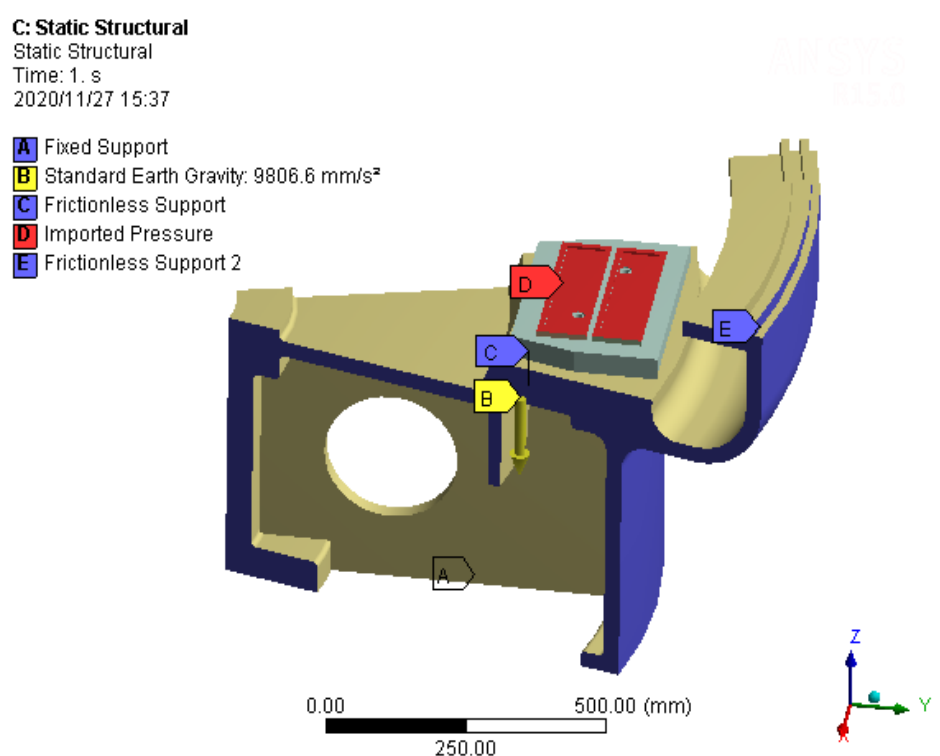

Fig. 12. Boundary conditions of base.

$\frac{\partial(\rho T)}{\partial t}+\operatorname{div}(\rho \vec{u} T)=\operatorname{div}\left(\frac{k}{c_{p}} \operatorname{grad} T\right)+S_{T}$

where $T$ is oil film temperature $(\mathrm{K}), S_{T}$ is heat source $(\mathrm{J})$.

\subsection{Heat Structure Interaction Equation}

The gap oil film temperature field and the oil recess pressure field are loaded as volume loads on the upper and lower surfaces of the hydrostatic bearing friction pair, and the friction pair deformation is solved by the thermal structure interaction method. Heat structure interaction equation is as follow.

$$
\left\{\begin{array}{c}
\sigma_{i j, j}+b_{2}(i)=0, i n \Omega \\
\sigma_{i j}=\mathrm{D}_{i j k l}\left(\varepsilon_{k l}+\mathrm{c}_{k l u_{1}}\right), i n \Omega \\
\varepsilon_{i j}=\frac{1}{2}\left[u_{2^{(i . j)}}+u_{2^{(j, i)}}\right], i n \Omega \\
u_{2}(i)=\overline{u_{2^{(i)}}, i n \Gamma_{u_{2}}} \\
\sigma_{i j} n_{j}=\overline{t_{2}(i)}, i n \Gamma \Gamma_{u 2}
\end{array}\right.
$$

where $\Omega$ is target domain, $\Gamma$ is target area boundary, $u_{2}(i)$ is displacement, $b_{2}(i)$ is volume components, $D_{i j k l}$ is structure flexibility matrix, $\varepsilon_{i j}, \sigma_{i j}, c_{k l}$ are strain, stress and thermal expansion coefficient respectively. 


\section{CONCLUSION Friction PAIRS DEFORMATION AND OIL FILM Clearance}

Boundary conditions of turntable and base are shown as Fig. 11 and Fig. 12. Under a load of $30 \mathrm{t}$, the rotational speed is from $10 \mathrm{r} / \mathrm{min}$ to $50 \mathrm{r} / \mathrm{min}$, the environment temperature is $20{ }^{\circ} \mathrm{C}$, the lubrication oil is No. 46, the deformation of the rotating table and the base is numerically simulated. Because the surface roughness is very small compared with the deformation of friction pair, the influence of surface roughness is not considered. The deformation of the rotational worktable and base at rotational speed of $50 \mathrm{r} / \mathrm{min}$ are shown in Fig. 13 and Fig. 14.

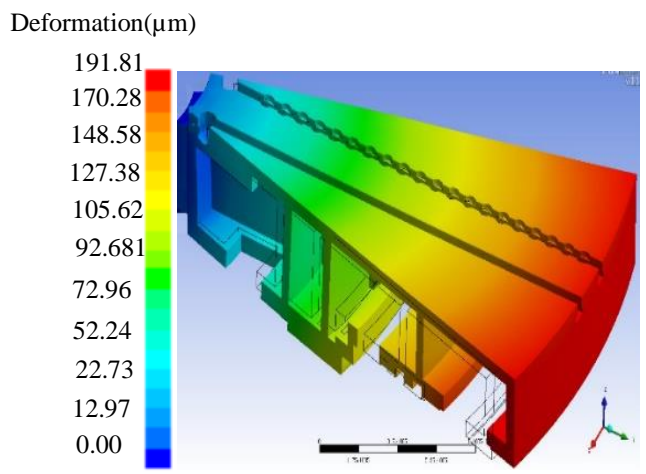

Fig. 13. Deformation of rotational worktable at 50r/min.

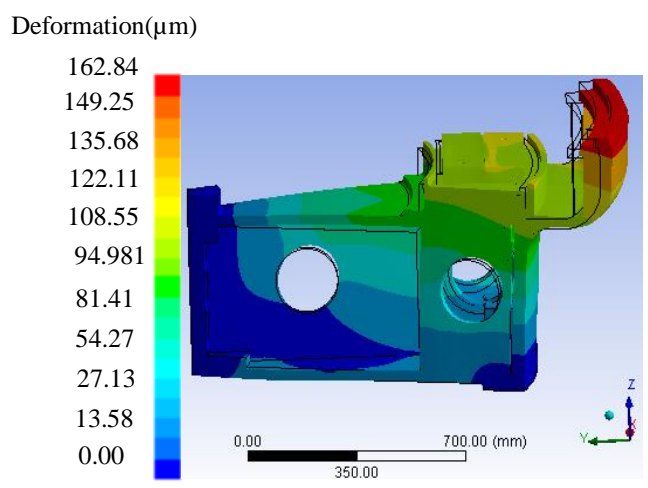

Fig. 14. Deformation of the base at 50r/min.

From Fig. 13, Fig. 14 and Fig. 15, it is found that the inside deformation of land is downward, and the outside deformation of land is upward. The deformation of downstream side of the land is upward, the deformation of upstream side of the land is downward. The inside deformation of the guide way is downward, while the outside deformation of the land is upward. The deformation of downstream side of the guide way is downward, the deformation of upstream side of the guide way is upward. Under the comprehensive influence of load, rotation speed and inclination angle, the deformation of friction pairs in the outside of the downstream side is the largest, the downward deformation of the guide way is the largest, and the upward deformation of the land is the largest. The oil film thickness in the outside of the downstream side is 2 the minimum, and the oil film shape is wedge shape from inside to outside in the radial direction and from downstream side to upstream side. These will lead to smaller oil outlet resistance, lower oil chamber pressure, local dry friction and loss of hydrostatic bearing capacity.

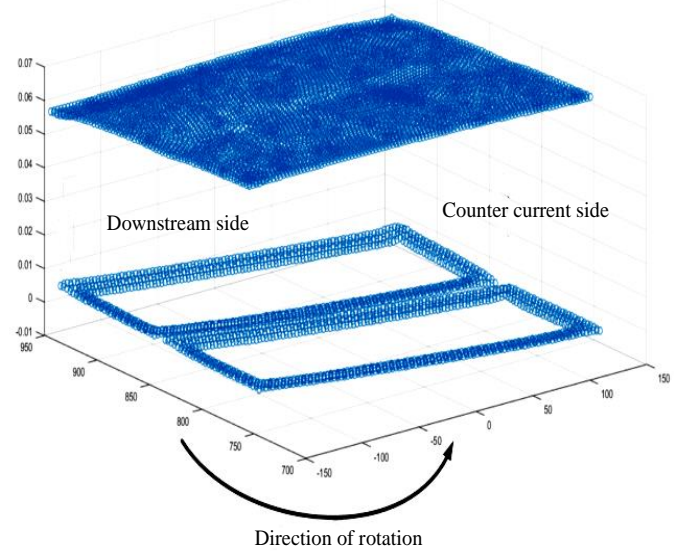

Fig. 15. Oil film morphology at 30t-50r/min.

\section{EXPERIMENTAL DETAILS}

In order to verify the correctness of theoretical analysis and numerical simulation, the measurement method of oil film thickness and hydrostatic bearing friction pair deformation was developed, the test rig was set up in the double columns vertical lathe of DVT500×50/150Q-N, the test rig was shown in Fig. 16. In order to accurately measure the friction pair deformation of hydrostatic workbench, four dial indicators are installed between the rotational worktable and the base, as shown in Fig. 17 and Fig. 18. The system can simultaneously measure the oil recess pressure, film thickness and oil film temperature, its digital instrument is shown in Fig. 19.

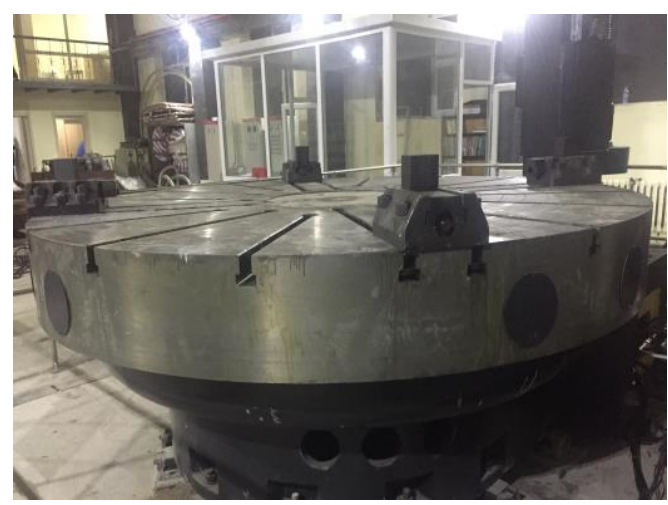

Fig. 16. Test rig of oil film thickness and hydrostatic bearing friction pair deformation. 


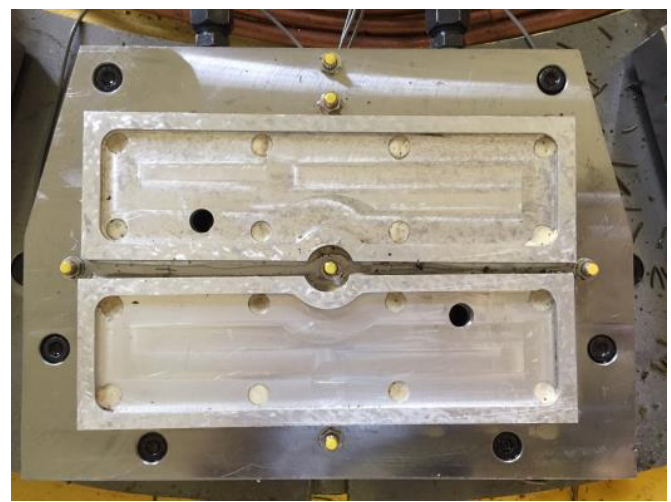

Fig. 17. Installation of oil film thickness sensors.

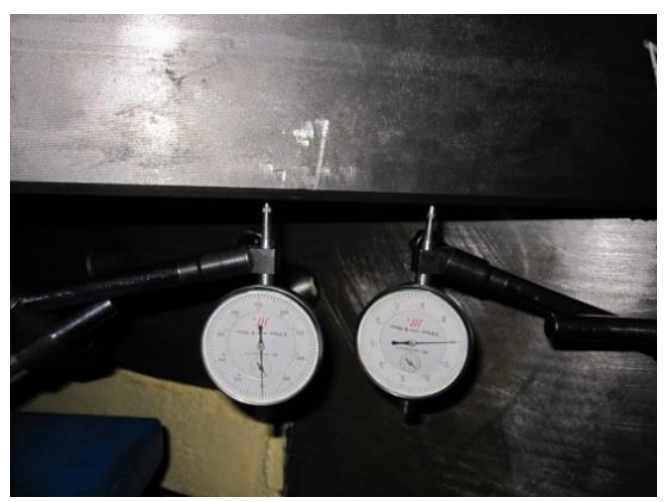

Fig. 18. Installation of dial indicator.

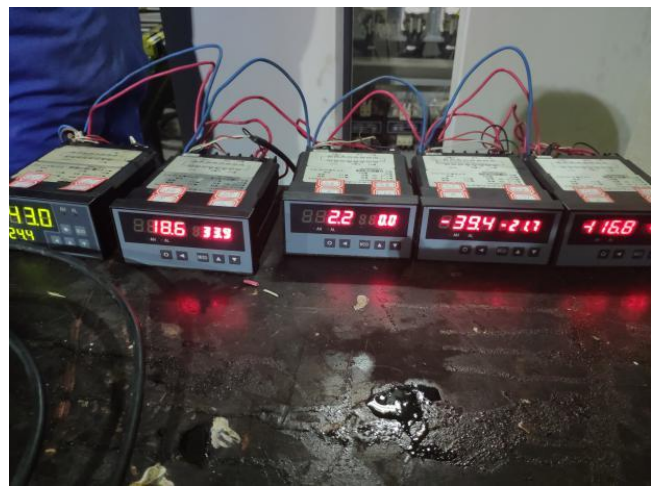

Fig. 19. Digital intelligent instrumentation.
In order to study the effect of rotational speed and load on friction pairs deformation, the deformations of the rotational worktable and base are simulated under a load of $30 \mathrm{t}$, and rotational speed are from $10 \mathrm{r} / \mathrm{min}$ to $50 \mathrm{r} / \mathrm{min}$, the lubrication oil is No. 46 compressed oil, flow rate of lubrication oil is 60 $\mathrm{L} / \mathrm{min}$, oil recess pressure range is in $0.6 \sim 1.0 \mathrm{MPa}$, and the environment temperature is $20^{\circ} \mathrm{C}$. The refrigerator is used to cool lubrication oil in order to guaranteed $20{ }^{\circ} \mathrm{C}$, and select a refrigerator power with $44 \mathrm{~kW}$. The tests are repeated 10 times, and the experimental data is obtained from the average value. Experimental data is shown in Table1.

From the experimental data in Table1, it is shown that oil film thickness decreased from $135 \mu \mathrm{m}$ to $90 \mu \mathrm{m}$, the clearance between bearing friction pairs decreased from $132 \mu \mathrm{m}$ to $92 \mu \mathrm{m}$. Clearance on the inner of friction pairs is $30 \mu \mathrm{m}$ less than that of on the outer of friction pairs, and the experimental value and the simulated value are in good agreement within the $8 \%$, and comparison curve between simulated and experimental values is shown in Fig. 20. If the rotational speed or load is further increased, dry friction or boundary lubrication will occur in the local position, and the friction failure will occur.

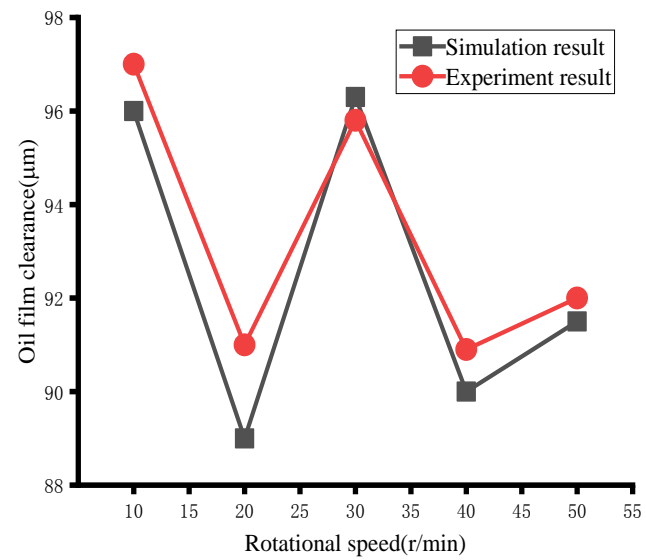

Fig. 20. Comparison between simulated and experimental values.

Table 1. Oil film thickness and clearance between friction pairs of different rotational speed under 30t load.

\begin{tabular}{|l|l|l|l|l|l|l|l|l|l|l|}
\hline $\begin{array}{l}\text { Runnin } \\
\text { g time } \\
(\mathrm{h})\end{array}$ & \multicolumn{4}{l}{ Oil film thickness $(\mu \mathrm{m})$} & \multicolumn{4}{l|}{ Friction pairs deformation $(\mu \mathrm{m})$} \\
\cline { 2 - 13 } & $10 \mathrm{rpm}$ & $20 \mathrm{rpm}$ & $30 \mathrm{rpm}$ & 40rpm & $50 \mathrm{rpm}$ & $10 \mathrm{rpm}$ & $20 \mathrm{rpm}$ & $30 \mathrm{rpm}$ & 40rpm & $50 \mathrm{rpm}$ \\
\hline 0 & 135 & 134 & 120 & 120 & 120 & 132 & 133 & 115 & 120 & 118 \\
\hline 1.0 & 125 & 140 & 125 & 120 & 110 & 112 & 113 & 100 & 103 & 101 \\
\hline 2.0 & 122 & 128 & 120 & 120 & 110 & 106 & 104 & 101 & 95 & 99 \\
\hline 3.0 & 124 & 130 & 130 & 118 & 110 & 103 & 101 & 98 & 93 & 91 \\
\hline 4.0 & 125 & 120 & 120 & 110 & 110 & 100 & 97 & 96 & 92 & 93 \\
\hline 5.0 & 125 & 123 & 125 & 106 & 104 & 98 & 93 & 97 & 92 & 94 \\
\hline 6.0 & 120 & 120 & 120 & 105 & 90 & 96 & 92 & 98 & 92 & 94 \\
\hline
\end{tabular}




\section{Conclusions}

The friction pair deformation of hydrostatic workbench is simulated by using heat fluid structure interaction method, and further micro-gap oil film morphology under the working conditions of highspeed and heavy-load is investigated, and experiment is designed to validate the proposed method. With increasing of rotational speed and load, oil film thickness becomes thinner, but rotational speed has a greater impact on the oil film thickness than that of load, and oil film thickness changes more quickly inside of oil sealing edge than that of outside. Due to the slight swing of the tilting oil pad, the oil film thickness of downstream side is smaller than that of upstream side. It is found that the clearance shape between friction pairs appears wedge from inside to outside along rotational worktable radius, and the maximum deformation position is at the corners of the oil sealing side outer oil cavity and the corresponding position on the lower surface of the hydrostatic rail of the rotating table in contact with it, and obtain the minimum oil film thickness, and the experiment results meet the simulation results. The friction behavior and failure mechanism of this kind of bearing are proved. If the rotational speed or load is further increased, dry friction or boundary lubrication will occur in the local position, and friction failure will occur.

\section{ACKNOWLEDGMENTS}

This research was financially supported by the National Natural Science Foundation of China (51375123) and the Natural Science Foundation of Heilongjiang Province (E2016040).

\section{REFERENCES}

ANSYS, Inc (2007). ANSYS CFX-Solver Modeling Guide, ANSYS, Inc.

Chai, H., W. Long, S. H. Yang, J. L. Lei and Y. H. Bi (2018). Effect of Gas-solid Thermal Coupling on Loading Capacity of Aerostatic Bearing Under Micro-scale Gas-film. Journal of Kunming University of Science and Technology (Natural Science) 43(5), 49-53.

Ding, H. B., Y. Y. Liu, Z. Q. Zheng and S. S. Li (2019). Analysis of Dynamic and Static Characteristics of High Speed Precision Grinder Spindle Bearing. Metrology and Measurement Technology 46(08), 82-85+93.

Guo, C. S. and Y. Cui (2016). Dynamic and Static Characteristics Analysis of Dynamic and Static Bearings for High Speed Precision Grinding Machine. Modular Machine Tool \& Automatic Manufacturing Technology 5, 17-21.

Huang, Y., H. Gao, C. Q. Zhang, Y. F. Liu and X. B. Li (2018). Optimization and Simulation of Cooling Structure Based on Temperature Induced Deformation Increasing of Hydrostatic Bearing. Hot Working Technology 47(16), 69-
$172+175$.

Luo, Z. H., J. Y. Yu, Y. F. Xu, H. Xi, G. Cheng, L. L. Yao, R. H. Song and K. D. Dearn (2021). Surface Characterization of Steel/Steel Contact Lubricated by PAO6 With Novel Black Phosphorus Nanocomposites. Friction 9(4), 723-733.

Mojtaba, M. V., A. Seyyed, N. Gandjalikhan and K. Zahra (2014). CFD-Based Thermohy Drodynamic Analysis of Rayleigh Step Bearings Considering an Inertia Effect. Tribology Transactions 57(1), 123-133.

Mustapha, L., E. Salah and B. Benyebka (2012). Elastohydrodynamic Lubrication Analysis of a Compliant Journal Bearing Considering Static and Dynamic Deformations of the Bearing Liner. Tribology Transactions 53(3), 349-368.

Novikov, E. A., I. A. Shitikov and V. A. Maksimov (2004). Calculation of the characteristics of a hydrostatic ring thrust bearing for refrigeration compressors. Chemical and petroleum Engineering 40(40), 23-26.

Saurabh, K. Y. and S. Satish C (2014). Performance of Hydrostatic Tilted Thrust Pad Bearings of Various Recess Shapes Operating with NonNewtonian Lubricant, Finite Elements in Analysis and Design 87, 43-55.

Stefan, I., M., B. J. Minel and B. M. Ana (2013). A Three-Dimensional Parametric Study and Numerical Experimental Flow Visualization of a Six-Pocket Hydrostatic Journal Bearing. Tribology Transactions 56(1), 1-26.

Tang, S. Y., Y. He and Y. Z. Wang (2017). Thermal Fluid Solid Coupling Analysis And Experimental Study of Dynamic And Static Pressure Bearing. Lubrication Engineering $42(8), 59-63$.

Wang, S. L. (2016). Research on Bearing Characteristics and Liquid-Solid-Thermal Coupling Law of Large-Scale and Heavy Burden Hydrostatic, Master thesis, Hunan University, Changsha, China.

Wang, Z. W., J. Zha, Y. L. Chen and W. H. Zhao (2014). Influencing of Fluid-structure Interactions on Static and Dynamic Characteristics of Oil Hydrostatic Guideways. Journal of Mechanical Engineering 50(9),48152.

Xu, Y. F., Q. Zheng, R. Abuflaha, D. Olson, O. Furlong, T. You, Q. Q. Zhang, X. G. Hu and W.T. Tysoe (2019a). Influence of Dimple Shape on Tribofilm Formation and Tribological Properties of Textured Surfaces under Full and Starved Lubrication. Tribology International 136, 267-275.

Xu, Y. F., Q. Zheng, J. Geng, Y. H. Dong, M. Tian, L. L. Yao and K. D. Dearn (2019b). Synergistic Effects of Electroless Piston Ring Coatings and Nano-additives in Oil on The Friction and Wear of A Piston ring/Cylinder 
X. D. Yu et al. / JAFM, Vol. 15, No. 2, pp. 505-513, 2022.

Liner Pair, Wear 422-423, 201-211.

Yu, X. D., S. W. Zhan, F. Han, F. K. Wang, F. Sun, D. B. Huang and J. H. Jiao (2021). Deformation Of Friction Pairs of Static and Dynamic Pressure Hybrid Bearing with Tilting Oil Pad. Engineering Mechanics 38(01), 241248.

Yu, X. D., W. C. Gao, G. P. Wu, W. K. Zhou, H. W. Bi, X. D. Yang and X. J. Zheng (2020). Thermal Characteristics of Hydrostatic Thrust Bearing under High Speed and Heavy Load Conditions. Journal of South China University of Technology (Natural Science Edition) 48(09), 79-85.

Yu, X. D., C. Liu, X. Zuo and Y. Q. Zhang (2018). Fluid-Thermal-Mechanical Coupled Solution and Experiment on Deformation of Bearing Friction Pairs In Hydrostatic Bearing. Engineering Mechanics 35(05), 231-238.

Zhang, C. (2016). Study On The Performance Of
Hydrostatic Bearing Oil Clearance By Bearing Shell-main Shaft Deformation, Master thesis, Chongqing University, Chongqing, China.

Zhang, Y. Q., Y. N. Feng, P. R. Kong, X. D. Yu and X. B. Kong (2019a). Temperature Field and Experiment of Hydrostatic Bearing Oil Film Based on Hot Oil Carrying, Journal of Jilin University (Engineering and Technology Edition) 49(04), 1203-1211.

Zhang, Y. Q., S. Q. Ni, Z. Q. Zhang, P. R. Kong, Y. N. Feng and X. B. Kong (2019b). Dynamic Lubrication Characteristics of Oil Film With Variable Viscosity Hydrostatic Sliding Bearing at High Speed. Journal of Mechanical Engineering 55(21), 108-117.

Zhang, Y. Q., Y. Feng, Y. Luo and X. D. Yu (2021). Hot Oil Carrying and Oil Film Temperature Rise Characteristics of Hydrostatic Thrust Bearings under Various Operating Conditions. Propulsion Technology 4(16), 1-9. 